\section{Ant Adurtess}

oN

\section{THE STATE AND THE PROFESSION.}

Bx JNU. MLLSON RHODES, M.D.,

Chairman of the South Manchester Division of the British Medical Assoctation, Alderman of the County Palatine of Lancaster.

My first duty is to thank you for the honour you have conferred upon me by electing me to fill this chair, and so adding one more to my already numerous public positions. As one who has played a part in pablic life for a quarter of a century, I am in a position to judge better than many men the relations that exist between the State and the profession.

In discussing this question I am no pessimist. I think that things are improving, that the Government departments at any rate recognize, by their actions, more than they ever did before that the old saying "Salus populi lex supreme" is the right one, but I trust they will go a little faster than they have done and will, in the future, act more on the advice of the sanitarian and give less attention to the clamour of the house sweater and the property jobber.

No one dreads more than I do a rise in rates, and I am fully aware that all the improvements that have been advocated by the medical profession must cost money, but there is on thing the public ought not to forget, and that is the credit side. When I commenced practice the mortality of England and Wales was 22,726 per million of the population. The last report of the Registrar-General gives the figures as 16,230-an enormous saving of life; perhaps the saving of life is better seen by stating that during the last thirty years, while the popnlation of England and Wales has increased by 10 millions, the gross mortality is actually less to-dag than it was then.

The wealth of the State depends upon the health of the nation, and this improvement in the health of the nation (and when I speak of the health of the people I am glad to think that the improvement is both in the physical and mental health of the nation as proved by the steady fall in the mortality from diseases of the nervous system) and improved sanitation has resulted in a reduction in the loss of wages from sickness or death; that loss a few years ago amounted to upwards of $£ 30,000,000$ in wages alone. whom is the credit of the reduction in the mortality, the improvement in the mental and physical health of the people, due, if not chiefly to the medical profession? The very knowledge the State possesses that the death-rate has diminished, has for its foundation our certificates (except a few coroner's cases). In spite of that fact, compare the treatment of the medical profession with that of the other officials dealing with the statistics of disease.

The State pays the Registrar-General, the superintendent registrars, the inspectors of registration, and the registrars. The State acknowledges, and rightly acknowledges, that these officials have a right to be paid, but when the members of the medical profession state the fact that they have as much right to be remunerated for their services, their claims are ignored, and they are refused bare justice for their professional services.

I am afraid that, at any rate in the past, sufferance has been too much the badge of all our tribe. We have not looked after our interests and we have not made those who are supposed to represent us to look after them as we ought to have done. At the present time you have in the House of Lords only one member of the profession, one who did really win the honour by his professional work for the welfare of humanity, Lord Lister. In the House of Commons you have a certain number of M.P.'s, but they are rari nantes in vasto gurgite, and in many cases they sit as party politicians and not professional men and they have neither had the weight or the position to which their knowledge entitles them.

Compare this state of affairs with the other learned professions-you have members of the legal profession all over both houses, from the Woolsack in the House of Lords, right through to the Speaker's chair in the House of Commons, and as you know, the House of Lords contains a whole bench full of Bishops.

Compare this state of affairs with the position of the medical profession.

During a quarter of a century of public life, I can only call to mind one member of the profession holding a ministerial position and that a secondary one, at the Local Government Board.

And that brings me to the question of the Local Government Board. I do not suppose there are six gentlemen here who can say who compose the Local Government Board, as constituted by. Act of Parliament. As a matter of law. the Local Government Board is, next to the Cabinet and the Privy Council, the most important body in the State. It is composed of -

The President of the Local Government Board.

The President of the Privy Conncil.

The Seoretary of State for the Home Department.

$$
\begin{array}{lllll}
\text { ", ", } & \text {," } & \text { Foreign } & \text { Colonial } & \text { ", } \\
\text { ", } & \text { ", } & \text { War } & \text { Indian }
\end{array}
$$

The Löd Privy Beal.

The Chancellor of the Exshequer.

More than a third of the Cabinet.

That is law and theory. As a matter of fact, I believe that the Local Government Board has met about twice in the last twenty years and then for a few minutes, to sign some legal documents.

The real Local Government Board, in a Parliamentary sense. is the President and the Secretary, who, of course, must rely to a great extent upon the advice of the Permanent Secretary and Assistant Secretary. There is not much difference between the term Local Government Board and the "we" of the leader writer in our daily papers.

Now I am quite aware that the inspectors, medical and general, and the other permanent officials are called in to advise, but that does not meet the case.

The work of the Local Government Board to-day, is a totally different thing from what it was when it came into existence thirty-one years ago. Your State fever hospitals, your smallpox hospitals, chronic asylums, epileptic hospitals, as State institutions, were almost unknown; to-day, as you know, their number is increasing by leaps and bounds, not in any sense due to any increase of disease-for statistics show, beyond the possibility of doubt, that the reverse is the case-but to the fact that the public are realizing more and more that to cure is the voice of the past; to prevent, the divine whisper of to-day.

How has the enormous increase of the work of the department that looks after the State hospitals been met? In the last twenty years you have had one additional medical inspector appointed, a sum total of two. The public do not jet grasp the importance of the so-called workhouse hospitals; perhaps it may help them to realize it when I say that there are more beds in the workhouse hospitals of London alone than there are in all the voluntary hospitals of England and Wales pat together. The people are streaming into the towns in an ever-increasing ratio, like it or not as we may; these hospitals will increase rather than diminish, and it is for the benefit of the taxpayer and patient that they should be made as efficient as possible. And I may say in passing, that, in my opinion, the Poor-law hospitals, excellent as they now are, do far less to pauperize the people than the so-called voluntary hospitals, the committees of which too often appear to be without an elementary knowledge of what really constitutes true charity. That, however, is a question that cannot be dealt with in the short time at my disposal, but which I hope will be dealt with faithfully.

I must get back to my subject. What I want to point out is that " new occasions teach new duties, time makes ancient good uncouth" and the medical staff of the Local Government Board are numerically unable to get through the work if they are to work reasonable hours.

What is required is a reconstitution of the Local Govern. ment Board, so that it may be more progressive in the future than it has been in the past. Why in the name of common sense should it not be once more a Board in fact as well as in name, something similar to the Conseil Supérieur d'Assistance Publique? You cannot do without your President and Parliamentary Secretary and the Permanent and Assistant Secretaries, but why should you not give seats on the Board to, say, the two chief general and medical inspectors and the heads of the legal and audit departments? I can see no reason why you should allow Commissioners in Lunacy to have seats at the Board and refuse gentlemen whose commission is in the Poor-law service. I think I know as much as anyone living of the relations between the Local Government Board and the officials, and no one acknowledges with more pleasure than I do the excellent work that Dr. Downes and Dr. Fuller have done, and I also recognize that the

[2327] 
relations between the Board and the profession are better, but I want to see them better still. The cardinal fault at the Local Government Board is that those in the office rarely come in contact with those outside the office, and they do not realize where the shoe pinches, therefore they have not that intimate knowledge of the subject that the medical and general inspectors have-a knowledge that should be utilized. If the medical and general inspectors were placed on the Board, I believe we should have far more harmonious working than we have had. Do not go away with the idea that I am condemning the Government department. On the contrary, the longer I have been in public life the more and more convinced I am of the necessity for the central power, and that there are a considerable number of things in which they ought to have more power than they have now. Specially important is this in regard to public appointments like those of medical officer of health, Union medical officers, and vaccinating officers. We have had recently reported, you are all aware, a very grave case of abuse of power by an incompetent council, and it is to be hoped at the coming election that the British Medical Association will make this a test question for candidates for Parliament.

And now, gentlemen, I turn for a few moments to another question, the administration of the Lunacy Laws. We all know the frightful state of affairs that existed when the Lunacy Commissioners were first esiablished, and probably with the laws dealing with mental diseases in a state of chaos, with many cases detained illegally as was then the case, there were reasons why there should be three Commissioners belonging to the legal and three to the medical profession, but, gentlemen, "new occasions teach new duties, time makes ancient good uncouth," and the necessity for the legal Commissioners has passed away. If one legal adviser is sufficient for Scotland, surely we can manage with two in England. The latest idea, I believe, is to increase the Lunacy Commissioners in England by one medical and one legal commissioner. No doubt the number of cases certified under the Lunacy Laws has increased enormously (as you know, that is no proof of an increase in lunacy) and the work of the Commissioners, the miserable detail work, has increased enormously. But is this the right way for the Government to deal with the reform of the Lunacy Laws? Of all the cases of the survival of the unfit that I am aware of, our system of the inspection of lunatics is the most striking example, because you have experts' time wasted on a mass of unnecessary details which benefit neither patient nor ratepayer.

You have I17,000 cases under the inspection of the six Commissioners in Lunacy, who are paid $£ \mathrm{I}, 5 \mathrm{co}$ a year each, at a total cost of $614,778-a$ by no means extravagant sum, say 8s. per head. But now let us turn to another class of insane, the insane under the care of the Court of Chancery. These number " about a thousand, of whom one-third are in private dwellings and the rest in asylums." To look after these you have two masters at $£ 2,000$ a year, and three visitors (two only medical) at $£ \mathrm{I}, 500$, a total cost of $£ 15,985$. I should like to ask, why should trained alienists have $f 500$ a year less than the legal gentlemen who probably had to gain their knowledge of lunacy entirely aiter they were appointed? And I should also like to ask, does it seem reasonable that 1,000 Chancery lunatics should cost $£ 2,000$ more than Ico, 000 cases under the care of the Lunacy Commissioners?

We have a right to demand that the profession shall receive justice at the hands of the State. So far, I am afraid, the wellknown lines of Byron are applicable to the treatment of too many of the officials of the Local Government Board. In advocating justice, I mean fixity of tenure. I do so quite as much in the interest of the public as the profession. When I was in the United States I carefully inquired into this question and found, as anyone would expect, that where you had practical fixity of tenure there you had a higher type of officer than where the period of office was terminable by some miserable Tammany organization. In the past age, even in the present, we have had great need of organization. I trust that by means of these district meetings we shall bring our forces into line and work for one common purpose. Once become united in our efforts, I believe we shall find the power that has been too far latent becoming active, and the profession will beable to make itself felt in the affairs of the State as it has a right to do.

Bequests to Medical Cearities.-Under the will of the late Miss Caroline Mary King, of St. Leonard's-on-Sea, the Ladies' Home and the Buchanan Hospital, both in that town, each receive a sum of $£$ 100.

\section{Remtarks}

ON

\section{THE PROFESSIONAL RELATIONS BETWEEN SPA DOCTORS AND THEIR BRETHREN.}

Rfad at a Meeting of the Harrogate Division of the Yorkshire Branch of the British Medical Association.

By ALBERT MOUILLOT, M.D., Harrogate.

IN March last Dr. Leonard Williams read a clever and tactful paper to the Balneological Society on the "Ethics of Health Resort Practice," which was followed by a discussion. 1 took part in the discussion, but it will not surprise those of you who know my limitations as a speaker to learn that thought of most of the points I wished to make after I had resumed my seat. The subject interested me greatly, and when invited by the executive of the Harrogate Medical Society to read a paper, I selected this subject as one which we might discuss amongst ourselves with advantage, but it was afterwards thought that this meeting would be a more suitable occasion, as we might have the advantage of hearing the opinions of those not engaged in Spa practice.

Dr. Leonard Williams charged health resort practitioners by implication with a neglect of correspondence, and an almost wilful desire to differ in points of diagnosis with those who send them patients. Now it is so obviously the interest of all reputableSpa doctors to keep on good terms with those who support them, by advising patients to consult them, that I feel sure that the complaints made against them must arise from misunderstanding of an avoidable nature, and it is with the object of helping to prevent these misunderstandings by showing how they occur, and how they could be avoided, that this paper has been written. I have used in the title the words, "professional relations," rather than the word "ethics," because many of the points suggested are in no wise obligatory in the sense that an ethical rule would be.

Patients who come for treatment to a Spa doctor may be divided into two classes : those who are sent directly to him by their medical men, and those who come by advice of a friend or relation. In my own practice I find the numbers are almost equal.

As I am of opinion that our duties are not quite the same in both classes, I intend treating them separately, taking the case of those sent directly by a medical man first.

Perhaps the best way of bringing all my points home is to begin in the consulting room of the doctor sending the patient, and end with the patient's last visit to the Spa doctor, stating what ought to be done by both doctors, in their own and their patient's interests, and afterwards showing how fasily neglect of any of the details may lead to misunderstandings, which, in their turn, may lead to breach of old friendship.

The practitioner, having decided as to the Spa to which he is going to send his patient, should then give the name and address of the doctor to whom he wishes to intrust him. If he should not happen to be able to recommend a name, he should, if time permits, endeavour to obtain one from some colleague. The patient should be told that a letter fully describing his case will be written and sent by post to the Spa doctor, while no suggestion as to what the treatment is likely to be should be made to the patient, or if any such suggestion be made, it should of course also be embodied in the letter. The patient should be asked to write to the Spa doctor a day or two in advance asking for an appointment.

Having promised to write, the doctor should do 80 at once, when the facts of the case are fresh in his mind. The letter should state the diagnosis arrived at, as well as any details of previous history or treatment he may deem necessary. As a rule the Spa doctor should have a fairly free hand as to treatment, but if the medical adviser has any decided views as to what ought to be done or left undone, those views should be stated.

If the doctor sending the patient attends to these points he will have done all in his power to prevent any difficulties arising. The patient will go to the doctor he has selected, and that doctor will have all the facts before him and the patient will have what is his right, the advantage of the combined intelligence of his advisers.

Now let us briefly state what may, and indeed does, happen if any of these apparently trivial points are omitted. In tha 